\title{
Recommendations for assessing patient-reported outcomes and health-related quality of life in patients with urticaria: a GA ${ }^{2}$ LEN taskforce position paper
}

\author{
I. Baiardini ${ }^{1 *}$, F. Braido ${ }^{1 *}$, C. Bindslev-Jensen ${ }^{2}$, P. J. Bousquet ${ }^{3}$, Z. Brzoza $^{4}$, G. W. Canonica ${ }^{1}$, \\ E. Compalati ${ }^{1}$, A. Fiocchi ${ }^{5}$, W. Fokkens ${ }^{6}{ }^{\prime}$ R. Gerth van Wijk ${ }^{7}$, A. Giménez-Arnau ${ }^{8}$, K. Godse $^{9}$, \\ C. Grattan ${ }^{10}$, J. J. Grob ${ }^{11}$, S. La Grutta ${ }^{12}$, D. Kalogeromitros ${ }^{13}$, E. Kocatürk ${ }^{14}$, C. Lombardi ${ }^{15}$, \\ A. Mota-Pinto ${ }^{16}$, E. Ridolo ${ }^{17}$, S. S. Saini ${ }^{18}$, M. Sanchez-Borges ${ }^{19}$, G. E. Senna $^{20}$, I. Terreehorst $^{6}$,
} A. Todo Bom ${ }^{21}$, E. Toubi ${ }^{22}$, J. Bousquet ${ }^{23,24}$, T. Zuberbier $^{25}$ \& M. Maurer ${ }^{25}$

${ }^{1}$ Allergy and Respiratory Diseases, Department of Internal Medicine, University of Genoa, Genoa, Italy; ${ }^{2}$ Department of Dermatology and Allergy Centre, Odense University Hospital, Odense, Denmark; ${ }^{3}$ University hospital, Department of Respiratory Medicine, Montpellier University, Montpellier, France; ${ }^{4}$ Department of Internal Diseases, Allergology and Clinical Immunology, Medical University of Silesia, Katowice, Poland; ${ }^{5}$ Department of Child and Maternal Medicine, The Melloni University Hospital, Milan, Italy; ${ }^{6}$ Department of Otorhinolaryngology, Academic Medical Centre, Amsterdam, the Netherlands; ${ }^{7}$ Section of Allergology, Department of Internal Medicine, Erasmus Medical Center, Rotterdam, the Netherlands; ${ }^{8}$ Department of Dermatology, Hospital del Mar, Universitat Autònoma de Barcelona, Spain; ${ }^{9}$ Shree Skin Centre and Pathology Laboratory, Navi Mumbai, Maharashtra, India; ${ }^{10}$ Cutaneous Allergy, St Johns, Institute of Dermatology, St Thomas Hospital, London and Dermatology Department, Norfolk and Norwich University Hospital, Norwich, UK; ${ }^{11}$ Service de Dermatologie, Hôpital Ste Marguerite, Marseille, France; ${ }^{12}$ Environment and Health Unit, ARPA Sicilia and Institute of Biomedicine and Molecular Immunology (IBIM), Italian National Research Council, Palermo, Italy; ${ }^{13}$ Allergy Unit, University General Hospital 'Attikon', Medical School of Athens, Athens, Greece; ${ }^{14}$ Department of Dermatology, Göztepe Training and Research Hospital, Istanbul, Turkey; ${ }^{15}$ Pneumoallergology Unit, S. Orsola FBF Hospital, Orsola, Brescia; ${ }^{16}$ Institute of General Pathology, Faculty of Medicine, University of Coimbra, Portugal; ${ }^{17}$ Department of Clinical Sciences, University of Parma, Parma, Italy; ${ }^{18}$ Department of Medicine, Division of Allergy and Clinical Immunology, Johns Hopkins University, Baltimore, MD, USA; ${ }^{19}$ Allergy and Immunology Department, Centro Médico-Docente La Trinidad, Caracas, Venezuela; ${ }^{20}$ Allergy Service, Verona Major Hospital, Verona, Italy; ${ }^{21}$ Immuno Allergology Department, Coimbra University Hospital, Coimbra, Portugal; ${ }^{22}$ Faculty of Medicine, Division of Allergy and Clinical Immunology, Bnai-Zion Medical Center, Technion, Haifa, Israel; ${ }^{23}$ Department of Respiratory Medicine, Montpellier University and INSERM U780, Montpellier; ${ }^{24}$ CESP, Inserm 1018, Villejuif, France; ${ }^{25}$ Department of Dermatology and Allergy, Allergie-Centrum-Charité/ECARF, Charité - Universitätsmedizin Berlin, Berlin, Germany

To cite this article: Baiardini I, Braido F, Bindslev-Jensen C, Bousquet PJ, Brzoza Z, Canonica GW, Compalati E, Fiocchi A, Fokkens W, Gerth van Wijk R, Giménez-Arnau A, Godse K, Grattan C, Grob JJ, La Grutta S, Kalogeromitros D, Kocatürk E, Lombardi C, Mota-Pinto A, Ridolo E, Saini SS, Sanchez-Borges M, Senna GE, Terreehorst I, Todo Bom A, Toubi E, Bousquet J, Zuberbier T, Maurer M. Recommendations for assessing patient-reported outcomes and health-related quality of life in patients with urticaria: a GA²LEN taskforce position paper. Allergy 2011; 66: 840-844.

\section{Keywords}

angioedema; disease burden; patientreported outcome; quality of life; urticaria.

\section{Correspondence}

Marcus Maurer, Department of

Dermatology and Allergy, Allergie-Centrum-

Charité, Charité - Universitätsmedizin Berlin,

Charitéplatz 1, 10117 Berlin, Germany.

Tel.: +4930450518043

Fax: +4930 450518972

E-mail: marcus.maurer@charite.de

${ }^{*}$ Both authors contributed equally.

Accepted for publication 15 February 2011

DOI:10.1111/j.1398-9995.2011.02580.x

\section{Abstract}

The aim of this Global Allergy and Asthma European Network (GA ${ }^{2}$ LEN) consensus report is to provide recommendations and suggestions for assessing patient-reported outcomes (PROs) including health-related quality of life in patients with urticaria. We recommend that PROs should be used both in clinical trials and routine practice for the evaluation of urticaria patients. We suggest that PROs should be considered as the primary outcome of future clinical trials. Two validated and disease-specific instruments for assessing PROs are available, the urticaria activity score (for symptoms) and the chronic urticaria questionnaire on quality of life $\mathrm{CU}-\mathrm{Q}_{2} \mathrm{OL}$. This latter tool, CU- $\mathrm{Q}_{2} \mathrm{OL}$, is available in many languages and should be preferred, where available, over more generic instruments for assessing urticaria-specific effects on quality of life. CU- $\mathrm{Q}_{2} \mathrm{OL}$ is only suited for the investigation of patients with chronic spontaneous urticaria. Similar instruments for other forms of urticaria have yet to be developed and validated. Also, tools for assessing other chronic spontaneous urticaria PROs besides quality of life and symptoms are needed.

Edited by: Hans-Uwe Simon 
Urticaria is a common skin disorder, characterized by itchy wheals and/or angioedema (1, 2). Many patients with urticaria remain afflicted beyond the acute stage by the condition, often for years, and nonacute urticaria has repeatedly been found to have a substantial impact on patient qualityof-life (QoL) (3-9). Recent reports have shown that patients with severe chronic spontaneous urticaria, mainly nonresponders to standard therapy, exhibit low levels of satisfaction with their physicians and treatments and that they expect their physicians to provide them with other and more effective therapies $(10,11)$. To better understand the impact of urticaria on affected patients and patients' views of their disease and its consequences, patient-reported outcomes (PROs) other than symptoms need to be consistently assessed in both clinical research and routine patient care $(12,13)$. Until now, very few randomized controlled trials have been published in which health-related QoL was assessed. Reviews that summarize urticaria patients' perspectives on the effects of their disease and treatment are largely missing. Currently, no randomized controlled trials in urticaria consider PROs other than symptoms and/or QoL. The consensus reached by the GA ${ }^{2}$ LEN task force for PROs assessment in clinical trials with allergic patients (14) and more specifically in respiratory allergy (15) supports the aim of this new Global Allergy and Asthma European Network $\left(\mathrm{GA}^{2} \mathrm{LEN}\right)$ consensus report. It is to provide information on the available instruments for PROs assessment in urticaria, to give recommendations and suggestions for PROs evaluation in clinical trials and routine medical practice, and to present areas of need for further research on PROs in urticaria.

\section{PROs evaluation in patients with urticaria as primary and secondary outcome in clinical trials}

Most clinical trials in spontaneous urticaria use symptom scores to assess disease activity and response to treatment, whereas for inducible urticaria, trigger thresholds are among the most common outcome parameters. As yet, only 10 trials have been performed, which analyze health-related QoL, in patients with chronic spontaneous urticaria. In six of these 10 trials health-related QoL, assessment is a secondary outcome.

As a trial's sample size calculation is based on the primary outcome, health-related QoL results from studies in which QoL is a secondary outcome which should be carefully evaluated.

As urticaria may have a substantial impact on the daily life of patients, we recommend the development of clinical trials in which PROs are evaluated as primary outcome of the study. A coprimary outcome in conjunction with other objective or physician-rated measurements, or a secondary outcome whose analysis is considered following a hierarchical sequence (16), is also recommended.

When PROs are used as secondary outcome, the sample size calculated for the primary endpoint should be adequate for demonstrating hypotheses made a priori on the PROs assessment (17). So far only one therapeutic trial in chronic spontaneous urticaria has used QoL as a primary outcome (18). When PROs evaluation is the end-point of an urticaria trial, an overview of the previous existing evidence, the reason for choosing this endpoint and the expected results must be provided. If exclusion criteria comprise patientrelated factors that could influence PROs assessment, this must be clearly stated. Relevant patient-related factors include mood, stress, alexithymia (i.e. the inability to express feelings with words), coping, psychosomatic comorbidity and influences, personality traits, or psychological variables.

\section{QoL assessment in patients with urticaria}

Quality-of-life in patients with chronic spontaneous urticaria has been measured with several different tools (Table 1). The use of generic tools allows for comparison of QoL impairment in patients with urticaria and patients with other conditions. Generic tools are not as sensitive as dermatology-specific or disease-specific instruments in detecting changes of QoL as a result of modifications in disease activity. Dermatology-specific instruments are especially helpful for comparing the impact of different diseases on patients' QoL. However, they are not as responsive to changes in QoL following modifications in the urticaria activity as disease-specific instruments. The chronic urticaria questionnaire on quality of life $\left(\mathrm{CU}-\mathrm{Q}_{2} \mathrm{OL}\right)$ is a unique disease-specific instrument for chronic spontaneous urticaria. It has been shown to be superior to less specific instruments in measuring the impact of the disease on patients' QoL. Also it was superior in comparing QoL impairment in different subsets of patients with chronic spontaneous urticaria and in assessing changes in QoL over time, e.g. in response to treatment. The use of symptom-specific instruments in patients with urticaria (e.g. ItchyQoL for assessing the impact of itch on QoL impairment (19) has not yet been reported (Tables 1 and 2).

Table 1 Examples for quality-of-life (QoL) instruments used in chronic spontaneous urticaria

\begin{tabular}{lll}
\hline Category & Instrument & References \\
\hline Generic & Medical Outcomes & $(8,29)$ \\
& Study (MOS) SF-36 & \\
& Nottingham Health & $(30,31)$ \\
& Profile (NHP) & \\
& World Health & $(32,33)$ \\
& Organisation & \\
& QOL-Brief & \\
& (WHOQoL-BREF) & \\
& Dermatological Life & $(4,9,34-36)$ \\
Dermatology-specific & Quality Index (DLQI) & $(3,5,10)$ \\
& Skindex & $(18,37,38)$ \\
& VQ Dermato & $(3,6,7,39,40)$ \\
Disease-specific & Chronic Urticaria - & \\
& Quality of Life & \\
& Questionnaire & \\
Symptom-specific & (CU-O ${ }_{2}$ oL) & \\
\hline & - & \\
\hline
\end{tabular}


Table 2 Quality-of-life (QoL) instruments and their use in urticaria trials and routine patient treatment

\begin{tabular}{|c|c|c|c|c|}
\hline \multirow[b]{2}{*}{ Objective } & \multicolumn{4}{|c|}{ Instrument category (Example) } \\
\hline & $\begin{array}{l}\text { Generic (SF-12/SF-36, } \\
\text { NHP, WHOQoL-Bref) }\end{array}$ & $\begin{array}{l}\text { Dermatology-specific } \\
\text { (DLQl, Skindex, VQ-Dermato) }\end{array}$ & $\begin{array}{l}\text { Disease-specific } \\
\left(\mathrm{CU}-\mathrm{Q}_{2} \mathrm{OL}\right)\end{array}$ & $\begin{array}{l}\text { Symptom-specific } \\
\text { (ItchyQol) }\end{array}$ \\
\hline $\begin{array}{l}\text { Compare QoL in patients } \\
\text { with different diseases }\end{array}$ & +++ & - & - & - \\
\hline $\begin{array}{l}\text { Compare } \mathrm{QoL} \text { in patients } \\
\text { with different skin conditions }\end{array}$ & + & +++ & - & - \\
\hline $\begin{array}{l}\text { Compare QoL in patients } \\
\text { with different urticaria } \\
\text { subpopulations }\end{array}$ & + & + & +++ & +-+++ \\
\hline Monitor QoL over time & $-/(+)$ & + & +++ & +-+++ \\
\hline $\begin{array}{l}\text { Monitor QoL in response to } \\
\text { treatment }\end{array}$ & $-/(+)$ & + & +++ & +-+++ \\
\hline $\begin{array}{l}\text { Assess symptom-specific } \\
\text { impact on QoL }\end{array}$ & - & - & - & +++ \\
\hline
\end{tabular}

- not suited; (+) somewhat/sometimes suited; + suited, ++ well suited, +++ ideally suited.

$\mathrm{CU}-\mathrm{O}_{2} \mathrm{OL}$, chronic urticaria questionnaire on quality of life.

\section{Methods for PROs evaluation in clinical urticaria trials}

The evaluation of PROs in clinical trials should make use of evidence-based medical protocols and procedures. If the trial is aimed at the investigation of the efficacy of a drug, a double blind randomised controlled design is recommended. If the trial investigates another kind of intervention besides drugs, a randomised controlled trial is recommended, with a double blind design if possible. Open-label studies, in which patients and investigators are aware of the assigned therapy, may bias the assessment of PROs.

The length of the trial will be determined by the nature of the disease (acute/chronic); however, the length should also be in line with the investigated PROs. The duration of previous studies performed to assess health-related QoL in chronic spontaneous urticaria is between 3 and 12 weeks. As chronic spontaneous urticaria - by definition - persists longer than 6 weeks, PROs assessment should be adapted to this duration. Also, the duration of trials should reflect that CU- $\mathrm{Q}_{2} \mathrm{OL}(2,11)$ as well as generic tools such as the Dermatological Life Quality Index (DLQI) or Skindex provide information on the patient's QoL during the previous one (DLQI, SKINDEX) or 2 weeks (CU- $\mathrm{Q}_{2} \mathrm{OL}$ ). In long-term trials, a periodical QoL assessment, taking into account the tool recall period, may provide a more comprehensive patient's perspective evaluation. It is important however that such a questionnaire is not submitted too often to the patient, because remembrance of the previous answers may bias responses.

\section{Choice of the PROs tool in clinical urticaria trials}

Currently, only two validated and urticaria-specific tools for PROs assessment are available: the urticaria activity score (UAS; for symptoms) and CU- $\mathrm{Q}_{2} \mathrm{OL}$ (for health-related qual- ity of life). Both tools are for chronic spontaneous urticaria only. Instruments for PROs assessment in patients with acute spontaneous urticaria or inducible urticaria are missing and have yet to be developed.

For chronic spontaneous urticaria, the UAS and CU$\mathrm{Q}_{2} \mathrm{OL}$, where available, should be preferred over the use of nonvalidated tools. In addition, the choice of the instrument must be made according to the aim of the study (i.e. if the impact on sleep is relevant, a tool suited for sleep assessment must be used) and the reason of the choice must be provided. When PROs assessment is done by use of a symptoms score, the UAS should be used according to current EAACI/ $\mathrm{GA}^{2} \mathrm{LEN} / \mathrm{EDF} / \mathrm{WAO}$ guidelines. Briefly, daily scores for numbers of wheals and intensity of pruritus are recorded and added for at least four consecutive days. Commonly, UAS scores of seven consecutive days, i.e. the UAS7, are used.

Patient-reported outcomes evaluation tools must also be chosen according to the characteristics of the study population in terms of age (proper age-related tool), socio-cultural background, and diseases phenotypes. Of the 10 published trials that evaluated health-related QoL in chronic spontaneous urticaria, eight used the DLQI or the SKINDEX, i.e. skin disease-specific questionnaires. Although they are well-validated tools, they have limitations as they are not specifically developed for patients with chronic spontaneous urticaria, but for dermatological diseases in general. In fact, they have been used for patients suffering from various clinical dermatological conditions such as eczema, lipodystrophy, skin cancer, ichthyosis, psoriasis, melasma, hyperhidrosis, and acne (20-27).

While highly specific tools targeted to chronic spontaneous urticaria (such as $\mathrm{CU}-\mathrm{Q}_{2} \mathrm{OL}$ ) are ideally suited to measure the effects of changes in disease activity, they do not allow for the comparison of QoL impairment with other disorders and 
can therefore not be used to rate the condition's impact on QoL within a group of disorders (allergic diseases or skin disorders, for instance). Furthermore, QoL is affected by many factors of which the presence of a disease is only one. A disease-specific QoL instrument is very sensitive in picking up the impact of the respective disease on QoL. But it is less sensitive than more general tools in picking up the impact of other factors that influence QoL. For instance, effects on QoL of a new drug for urticaria that influences a QoL dimension not usually affected by chronic spontaneous urticaria may be overlooked in a trial using a specific tool, but not by a more generic instrument.

When the impact on PROs including health-related QoL of a specific symptom needs to be explored, a symptomspecific tool should be used (when available) in addition to a disease-specific questionnaire. For example, ItchyQoL, a symptom-specific questionnaire for assessing QoL-impairment due to pruritus, and $\mathrm{CU}-\mathrm{Q}_{2} \mathrm{OL}$ should be used to determine the impact of pruritus on patients with chronic spontaneous urticaria (Table 2).

The high prevalence of psychosomatic comorbidity and influences and their significant burden on patients' QoL should be considered when investigating chronic spontaneous urticaria $(5,28,29)$. The role of psychological characteristics and personality traits in determining the subjective experience of patients with chronic spontaneous urticaria still remains largely unexplored $(30,31)$.

In trials assessing the effects of an intervention, the choice of the PROs tool will be made according to the expected intervention effects. Whenever available a tool specific for the outcome (e.g. sleep, satisfaction, etc.) should be used.

\section{PROs assessment in routine clinical practice}

Both, the UAS and the $\mathrm{CU}-\mathrm{Q}_{2} \mathrm{OL}$ are suited and recommended for the use in routine clinical practice. These PROs tools can be used to determine disease activity impact as well as changes in disease activity impact including those in response to therapy. However, more generic instruments such as those adapted for chronic skin disorders may also be used.

\section{Unmet needs in PROs assessment in urticaria}

1 There are currently no tools a) for the assessment of other PROs besides QoL and symptoms in chronic spontaneous urticaria, b) for PROs assessment in patients with inducible urticaria, c) for PROs assessment in children and adolescents with urticaria or their parents, and d) for PROs assessment in partners of patients with urticaria.

2 The impact of doctor/patient communication on PROs needs investigation as currently urticaria patients' and doctors' view on the quality of their relationship differ significantly.

3 Minimal important differences for PROs instruments as well as the suitability of PROs tools to categorize disease activity as mild, moderate, or severe remain to be investigated in detail and published.

4 The assessment of relationships between different PROs and psychological variables is needed.

5 The transvalidation in different languages, and not only the translation, of the main instruments for PROs assessment, or the generation of international instruments is needed.

\section{References}

1. Zuberbier T, Asero R, Bindslev-Jensen C, Canonica GW, Church MK, Giménez-Arnau AM et al. EAACI/GA2LEN/EDF/ WAO guideline: definition, classification and diagnosis of urticaria. Allergy 2009;64:14171426.

2. Zuberbier T, Asero R, Bindslev-Jensen C, Canonica GW, Church MK, Giménez-Arnau $\mathrm{AM}$ et al. EAACI/GA ${ }^{2} \mathrm{LEN} / \mathrm{EDF} /$ WAO Guideline:Management of Urticaria. Allergy 2009;64:1427-1443.

3. Mlynek A, Magerl M, Hanna M, Lhachimi S, Baiardini I, Canonica GW et al. The German version of the chronic urticaria quality of life questionnaire $\left(\mathrm{CU}-\mathrm{Q}_{2} \mathrm{OL}\right)$ : factor analysis, validation and initial clinical findings. Allergy 2009;64: 927-936.

4. Mlynek A, Zalewska-Janowska A, Martus P, Staubach P, Zuberbier T, Maurer M. How to assess disease activity in patients with chronic urticaria. Allergy 2008;63:777780.

5. Staubach P, Eckhardt-Henn A, Dechene M, Vonend A, Metz M, Magerl M et al. Quality of life in chronic urticaria is differentially impaired and determined by psychiatric comorbidity. Br J Dermatol 2006;154:294-298

6. Valero A, Herdman M, Bartra J, Ferrer M, Jáuregui I, Dávila I et al. Adaptation and validation of the Spanish version of the chronic urticaria quality of life questionnaire. J Investig Allergol Clin Immunol 2008;18:426-432.

7. Baiardini I, Pasquali M, Braido F, Fumagalli F, Guerra L, Compalati E et al. A new tool to evaluate the impact of chronic urticaria on quality of life: chronic urticaria quality of life questionnaire. Allergy 2005;60:1073-1078.

8. Baiardini I, Giardini A, Pasquali M, Dignetti P, Guerra L, Specchia C et al. Quality of life and patients' satisfaction in chronic urticaria and respiratory allergy. Allergy 2003;58:621-623.

9. Lennox RD, Leahy MJ. Validation of the dermatology life quality index as an outcome measure for urticaria related quality of life. Ann Allergy Asthma Immunol 2004; 93:142-146.

10. Maurer M, Ortonne JP, Zuberbier T. Chronic urticaria: a patient survey on qual- ity of life, treatment usage and doctorpatient relationship. Allergy 2009;64:581588.

11. Maurer M, Ortonne JP, Zuberbier T. Chronic urticaria: a patient survey on health behaviors, symptom patterns, and treatment needs. Br J Dermatol 2009;160:633-641.

12. Grob JJ, Gaudy-Marqueste C. Urticaria and quality of life. Clin Rev Allergy Immunol 2006;30:47-51.

13. Grob JJ, Lachapelle JM. Non-sedating antihistamines in the treatment of chronic idiopathic urticaria using patient-reported outcomes. Curr Med Res Opin 2008;24: 2423-2428.

14. Baiardini I, Bousquet PJ, Brzoza Z, Canonica GW, Compalati E, Fiocchi A et al. Recommendations for assessing patientreported outcomes and health-related quality of life in clinical trials on allergy: a $\mathrm{GA}^{2} \mathrm{LEN}$ taskforce position paper. Allergy. 2010;65:290-295.

15. Braido F, Bousquet PJ, Brzoza Z, Canonica GW, Compalati E, Fiocchi A et al. Specific recommendations for PROs and HRQoL assessment in allergic rhinitis and/or asthma: 
a GA ${ }^{2} \mathrm{LEN}$ taskforce position paper. Allergy 2010;65:959-968.

16. US Department of Health and Human Services FDA Center for Drug Evaluation and Research, US Department of Health and Human Services FDA Center for Biologics Evaluation and Research and US Department of Health and Human Services FDA Center for Devices and Radiological Health, Guidance for industry: patient reported outcome measures: use in medical product development to support labelling claims: draft guidance. Health Qual Life Outcomes 2006; 4:79.

17. European Medicines Agency. Committee for medicinal products for human use (CHMP). Reflection paper on the regulatory guidance for the use of health-related quality of life (HRQoL) measures in the evaluation of medicinal products. EMEA/CHMP/EWP/ 139391/2004 European Medicines Agency website. Available at: http://www.ema.europa.eu/docs/en_GB/document_library/Scientific_guideline/2009/09/WC500003637.pdf. Accessed October 2010.

18. Grob JJ, Auquier P, Dreyfus I, Ortonne JP. How to prescribe antihistamines for chronic idiopathic urticaria: desloratadine daily vs PRN and quality of life. Allergy 2009;64:605-612.

19. Desai NS, Poindexter GB, Monthrope YM, Bendeck SE, Swerlick RA, Chen SC. A pilot quality-of-life instrument for pruritus. $J \mathrm{Am}$ Acad Dermatol 2008;59:234-244.

20. Wallenhammar LM, Nyfiall M, Lindberg M, Meding B. Health-related quality of life and hand-eczema -a comparison of two instruments, including factor analysis. $J$ Invest Dermatol 2004;122:1381-1389.

21. Blanch J, Rousand A, Martinez E, De Lazzari E, Milinkovic A, Peri JM et al. Factors associated with severe impact of lipodystrophy on the quality of life of patients infected with HIV-1. Clin Infect Dis 2004;38:14641470.

22. Rhee JS, Matthews BA, Neuburg M, Smith TL, Burzynsky M, Nattinger AB. Skin cancer and quality of life: assessment with the
Dermatology Life Quality Index. Dermatol Surg 2004;30:525-529.

23. Genemo A, Sjoden PO, Johansson E, Vahlquist A, Lindberg M. Health-related quality of life among patients with ichthyosis. Eur $J$ Dermatol 2004;14:61-66.

24. E.Bergstrom KG, Arambula K, Kimball AB. Medication formulation affects quality of life: a randomized single-blind study of clobetasol propionate foam $0.05 \%$ compared with combined program of clobetasol cream $0.05 \%$ for the treatment of psoriasis. Cutis 2003;72:407-411.

25. Balkrishnan R, McMichael AJ, Camacho FT, Saltzberg F, Housman TS, Grummer S et al. Development and validation of a health-related quality of life instrument for women with melasma. Br J Dermatol 2003;149:572-577.

26. Campanati A, Penna L, Guzzo T, Menotta L, Silvestri B, Lagalla G et al. Quality-of-life assessment in patients with hyperhidrosis before and after treatment with botulinum toxin: results of an open-label study. Clin Ther 2003;25:298-308.

27. Newton JN, Mallon E, Klassen A, Ryan TJ, Finlay AY. The effectiveness of acne treatment: an assessment by patients of the outcome of therapy. Br J Dermatol 1997; 137:563-567.

28. Brzoza Z, Kasperska-Zajac A, BaduraBrzoza K, Matysiakiewicz J, Hese RT, Rogala B. Decline in dehydroepiandrosterone sulphate observed in chronic urticaria is associated with psychological distress. Psychosom Med 2008;70:723-728.

29. Ozkan M, Oflaz SB, Kocaman N, Ozseker F, Gelincik A, Büyüköztürk S et al. Psychiatric morbidity and quality of life in patients with chronic idiopathic urticaria. Ann Allergy Asthma 2007;99:29-33.

30. O’Donnell BF, Lawlor F, Simpson J, Morgan M, Greaves MW. The impact of chronic urticaria on the quality of life. Br J Dermatol 1997;136:197-201.

31. Berrino AM, Voltolini S, Fiaschi D, Pellegrini S, Bignardi D, Minale P et al. Chronic urticaria: importance of a medico- psychological approach. Eur Ann Allergy Clin Immunol 2006;38:149-152.

32. Engin B, Uguz F, Yilmaz E, Ozdemir M, Mevlitoglu I. The levels of depression, anxiety and quality of life in patients with chronic idiopathic urticaria. Euro Acad Dermatol and Venereol 2008;22:36-40.

33. Uguz F, Engin B, Yilman E. Quality of life in patients with chronic idiopathic urticaria: the impact of axis I and axis II psychiatric disorders. Gen Hosp Psychiatry 2008;30:453457.

34. Shikar R, Harding G, Leathy M, Lennox RD. Minimal important difference (MID) of the dermatology life quality index (DLQI): results from patients with chronic urticaria. Health Qual Life Outcomes 2005;3:36.

35. Staubach P, Onnen K, Vonend A, Metz M, Siebenhaar F, Tschentscher I et al. Autologous whole blood injections to patients with chronic urticaria and a positive autologous serum skin test: a placebo-controlled trial. Dermatology 2006;212:150-159.

36. Magerl M, Pisarevskaja D, Scheufele R, Zuberbier T, Maurer M. Effects of a pseudoallergen-free diet on chronic spontaneous urticaria: a prospective trial. Allergy 2010;65:78-83.

37. Grob JJ, Revuz J, Ortonne JP, Auquier P, Lorette G. Comparative study of the impact of chronic urticaria, psoriasis, and atopic dermatitis on the quality of life. $\mathrm{Br} J$ Dermatol 2005;152:289-295.

38. Grob JJ, Auquier P, Dreyfus I, Ortonne JP. Quality of life in adults with chronic idiopathic urticaria receiving desloratadine: a randomised, double-blind, multicentre, placebo-controlled study. $J$ Eur Acad Dermatol Venereol 2008;22:87-93.

39. Yadav MK, Rishi JP, Nijawan S. Chronic urticaria and helicobacter pylori. Indian $J$ Med Sci 2008;62:157-162.

40. Bunselmeyer B, Laubach HJ, Schiller M, Stanke M, Luger TA, Brehler R. Incremental build-up food challenge - new diagnostic approach to evaluate pseudoallergic reactions in chronic urticaria. Clin Exp Allergy 2009;39:116-126. 